\title{
Gastric pancreatic heterotopia: an unusual cause of upper gastrointestinal bleeding
}
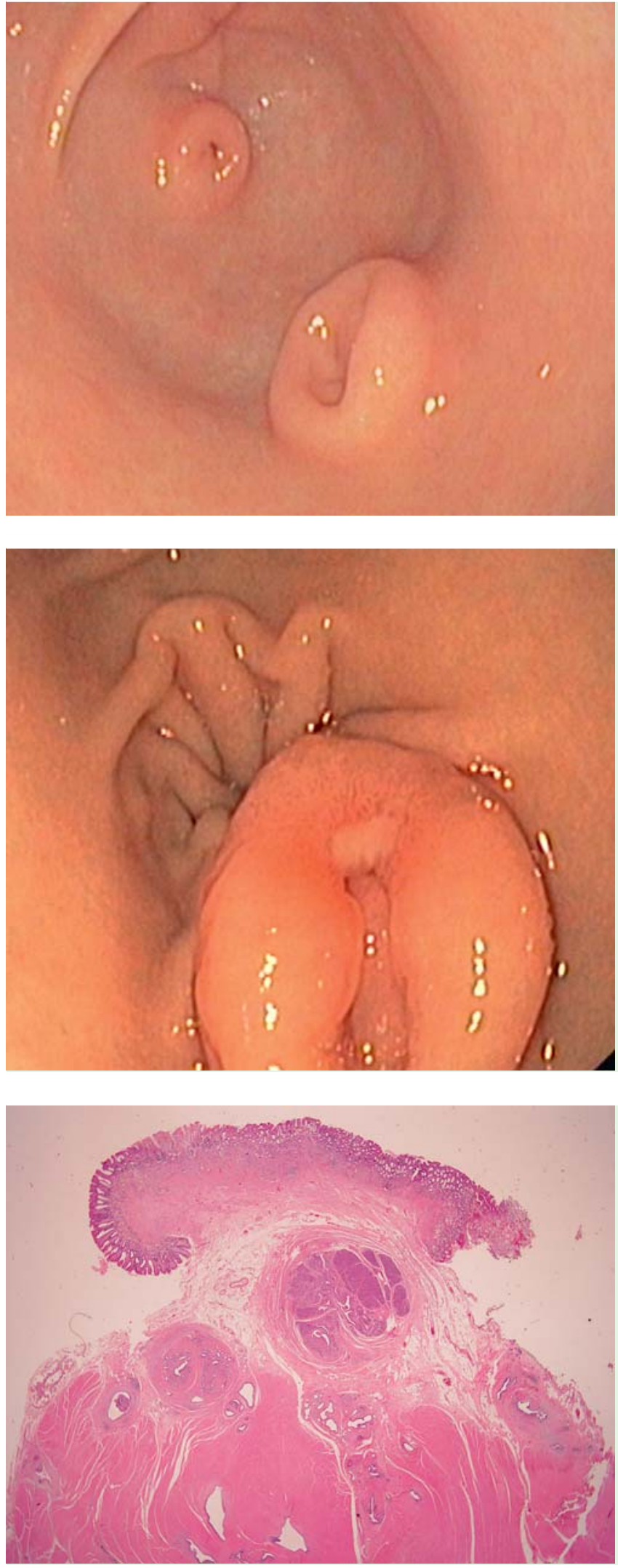

Fig. 1 Endoscopic view showed two typical submucosal, ovalshaped lesions with central umbilication at the antrum in a 28-yearold woman with history of chronic intermittent anemia and dark stool.

Fig. 3 A clean-based ulcer on the larger lesion.

Fig. 4 Histopathologic section of the gastric subepithelial lesion showing the submucosal nodule composed of lobulated clusters of pancreatic acini and the ductal structure with periductal mucous glands in the center.

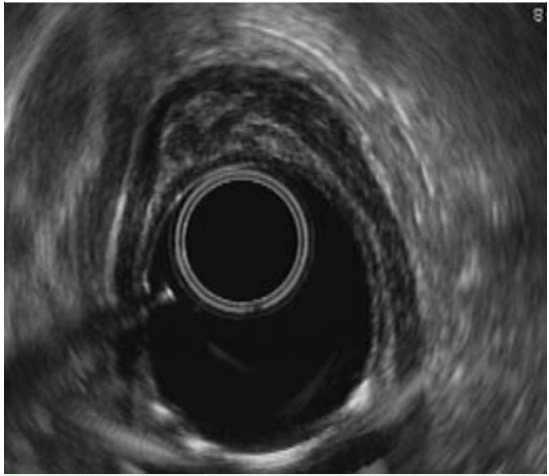

Fig. 2 Endosonographic view showing a heterogeneous, hypoechogenic mass arising from the third layer of the gastric wall.

A 28-year-old woman presented with history of chronic intermittent anemic symptoms with dark stool for few years. Her blood tests showed a low hemoglobin level $(6.6 \mathrm{mg} / \mathrm{dL})$. She underwent esophagogastroduodenoscopy (EGD), which revealed two subepithelial lesions, diameter $1.0 \mathrm{~cm}$ and $1.5 \mathrm{~cm}$ and with central umbilication, located in the antral area. These endoscopic findings typically suggested pancreatic rests ( Fig. 1). She underwent colonoscopy, video-capsule enteroscopy, Meckel's scan, and single-balloon enteroscopy, with negative results. An endosonographic study of one subepithelial lesion showed a hypoechoic lesion with central anechoic area arising from the third layer of the gastric wall, consistent with the diagnosis of pancreatic rest ( $\bullet$ Fig.2). During the intensive investigations the patient continued to have intermittent acute anemia, requiring several blood transfusions. The last time she presented with black color stool with anemia, she underwent EGD again, which showed an acute, clean-based ulcer on of the larger pancreatic rest lesion ( Fig.3). She was referred for surgery (laparoscopy-assisted wedge resection of the stomach) and pathological examination confirmed presence of pancreatic rests ( Fig.4). At 6 months follow-up the patient was doing well without any recurrence of bleeding. The pancreatic rest (also called pancreatic heterotopia, aberrant pancreas, heterotopic pancreas and accessory pancreas) consists of normal pancreatic tissue in an ectopic location. In a case series reported by Chen et 
al. in 2008, only a third of the patient were symptomatic (abdominal pain, abdominal distention, and gastrointestinal bleeding in $60 \%, 15 \%$, and $30 \%$, respectively) [1]. There are a few reports of gastrointestinal hemorrhage related to this lesion, but bleeding from gastric pancreatic heterotopia is very rare and usually occurs in relation to a large lesion [2]. The more common location of pancreatic heterotopia with bleeding is in the small intestine [3]. The few cases reports of gastric pancreatic rests along with bleeding from Meckel's diverticulum did not find a clear association between the two.

Endoscopy_UCTN_Code_CCL_1AB_2AD_3AZ

Competing interests: None

\section{Prachayakul', P. Aswakul², M. Deesomsak ${ }^{2}$, A. Pongpaibul ${ }^{3}$}

1 Siriraj GI Endoscopy Center, Division of Gastroenterology, Department of Internal Medicine, Faculty of Medicine Siriraj Hospital, Mahidol University, Bangkok, Thailand

${ }^{2}$ Liver and Digestive Institute, Samitivej Sukhumvit Hospital, Bangkok, Thailand

${ }^{3}$ Department of Pathology, Faculty of Medicine, Siriraj Hospital, Mahidol University, Bangkok, Thailand

\section{References}

1 Chen HL, Chang WH, Shih SC et al. Changing pattern of ectopic pancreas: 22 years of experience in a medical center. J Formos Med Assoc 2008; 107: 932-936

2 Yuan Z, Chen J, Zheng $Q$ et al. Heterotopic pancreas in the gastrointestinal tract. World J Gastroenterol 2009; 15: 3701 -3703

3 Tomita S, Kang J, Ghassemi M. Heterotopic pancreas - an unusual cause of melena in a pediatric patient. J Ped Surg 2009; 44: $2432-2437$

\section{Bibliography}

DOI http://dx.doi.org/

10.1055/s-0032-1326120

Endoscopy 2013; 45: E7-E8

(c) Georg Thieme Verlag KG

Stuttgart · New York

ISSN 0013-726X

\section{Corresponding author}

\section{Prachayakul}

Division of Gastroenterology,

Department of Internal Medicine

Faculty of Medicine

Siriraj Hospital

Mahidol University

Bangkok

Thailand 10700

Fax: +662-4196101

kaiyjґ@gmail.com 